\title{
ANALYSIS OF MOLECULAR MARKERS AS IL-12, IL-22 AND IFN-y IN CORRELATION WITH A CLINICAL COURSE IN PATIENTS WITH PSORIASIS
}

\author{
MAGDALENA KUTWIN', MONIKA MIGDALSKA-SĘK², EWA BRZEZIAŃSKA-LASOTA², \\ PIOTR ZELGA ${ }^{3}$, and ANNA WOŹNIACKA ${ }^{1}$
}

Medical University of Lodz, Łódź, Poland

${ }^{1}$ Department of Dermatology and Venereology

${ }^{2}$ Department of Biomedicine and Genetics

${ }^{3}$ Department of General and Colorectal Surgery

\begin{abstract}
Objectives: As a chronic, recurrent, immunologically mediated systemic disease and a common cause of dermatological problems, psoriasis is often a subject of scientific research. Skin changes located on the hands can cause difficulties and limitations in the performance of professional activities, especially manual ones. The main role in pathogenesis is played by immunological factors - improper functioning of the components of the immune system, among others, T lymphocytes and cytokines like interleukin-12 (IL-12), interleukin-22 (IL-22) and interferon gamma (IFN- $\gamma$ ). Material and Methods: The obtained tissue and blood were destined for RNA isolation. The RNA was then subjected to a reverse transcription reaction. The relative gene expression level was evaluated by the real-time polymerase chain reaction for $I L-12 B, I L-22$ and $I F N-\gamma$ genes, and presented as the relative quantification (RQ) value, relative to the reference gene $G A P D H$. In addition, a correlation analysis of the expression level of selected genes with the clinical course of the disease, as assessed by the Psoriasis Area and Severity Index (PASI), the Body Surface Area (BSA) and the Dermatology Life Quality Index (DLQI) scores was performed. Results: Statistical analysis confirmed a significant increase in RQ values for $I L-12 B, I L-22$ and $I F N-\gamma$ in the group of psoriatic patients vs. the control group. A positive correlation was also found between BSA and PASI and RQ for the $I L-12 B$ gene. Conclusions: Increased expression levels of $I L-12 B, I L-22$ and $I F N-\gamma$ genes in psoriatic skin confirm that selected cytokines play an important role in the initiation and sustenance of psoriasis. Int J Occup Med Environ Health. 2020;33(5):635-47
\end{abstract}

Key words:

psoriasis, disease activity, proinflammatory cytokines, skin disease, immunology, molecular markers

\section{INTRODUCTION}

Psoriasis is a chronic, recurrent, genetically conditioned dermatosis with autoimmune background, associated with inflammatory-proliferative processes in the skin. It applies even to $2 \%$ of the Caucasian population [1-4]. Skin changes located on the hands can cause difficulties and limita- tions in the performance of professional activities, especially manual ones. Until now, the cause of this disease, as well as the mechanisms leading to its development, have not been fully understood, but some environmental factors, which aggravate or even trigger psoriatic lesions, are known. The most important are infectious agents (mainly

Funding: this work was supported by the Medical University of Lodz, Poland (grant No. 503/1-152-01/503-11-002).

Received: July 7, 2019. Accepted: April 30, 2020.

Corresponding author: Magdalena Kutwin, Medical University of Lodz, Department of Dermatology and Venereology, pl. Hallera 1, 90-647 Łódź, Poland (e-mail: kutwin1989@gmail.com). 
streptococci and staphylococci), disturbance of cutaneous and intestinal microbiom, some drugs (e.g., $\beta$-blockers, nonsteroidal anti-inflammatory drugs, lithium), skin injuries, addictions (tobacco and alcohol intake), unhealthy diet leading to obesity, and stress [5-7]. Until recently, it was thought that the major role in psoriasis pathogenesis was played by T-helper 1 (Th1) lymphocytes stimulated by interleukin-12 (IL-12) and interferon gamma (IFN- $\gamma$ ). Recent studies, however, have highlighted the key function of both innate and acquired immune responses with the dominant effects of T-helper 17 (Th17) lymphocytes and their associated cytokines, which include interleukin-22 (IL-22), interleukin-17 (IL-17), interleukin-23 (IL23) and tumor necrosis factor alpha (TNF- $\alpha$ ).

It is believed that IL-12 acts on naive T lymphocytes and initiates Th1 response, and IL-23 supports inflammatory reaction, which is regulated by Th1. The inflammation initiated by Th1 stimulates Th17 activity, supporting the induced inflammatory reaction [8]; T-helper 22 (Th22) lymphocytes, through IL-22, regulate the function of keratinocytes, mainly in the process of skin response to infection [9]; and IL-22 together with TNF- $\alpha$, by stimulating chemokines and recruitment of neutrophils, activates metalloproteinases, which leads to the degradation of connective tissue stroma.

\section{Aim of the study}

The aim of the study is to assess the expression level (relative quantification [RQ]) of selected genes: $I L-12, I L-22$ and $I F N-\gamma$ in T-regulatory cells in blood and skin biopsies taken from patients with psoriasis. The results obtained were correlated with healthy volunteers. All parameters were compared to the clinical indicators of the activity and severity of the disease process.

\section{MATERIAL AND METHODS}

\section{Clinical features of patients and skin samples}

The research covered a group of 30 adults suffering from plaque psoriasis - 10 women (30\%) and 20 men (70\%), aged $21-81$ years (mean age: $53.73 \pm 15.74$ years). The patients were treated in the Department of Dermatology and Venereology and/or the Diagnostic and Treatment Center of Skin Diseases in March 2016-July 2017. After obtaining written consent forms from the patients, a sample (diameter: $4 \mathrm{~mm}$ ) was taken from the areas of skin lesions using the punch-biopsy method, and $10 \mathrm{ml}$ of venous whole blood was collected for the ethylenediaminetetraacetic acid (EDTA) anticoagulant. In assessing the severity of skin lesions, the Psoriasis Area and Severity Index (PASI), the body surface area (BSA) and the Dermatology Life Quality Index (DLQI) scores were used.

The first of them, PASI, combines the assessment of the extent and severity of skin lesions. It determines the percentage of skin affected by psoriatic lesions in 4 areas: head, upper limbs, trunk and lower limbs. Then, within each location, the morphology of lesions, i.e., erythema and infiltration within them, as well as stratification of the scales in the range from 0 - "no change" to 4 - "very strong intensity," is assessed. After proper results multiplication, a value of $0-72 \mathrm{pts}$ is obtained. The greater the number of points, the greater the severity of psoriasis [10-14].

The BSA indicator determines the percentage of the body surface area covered by psoriatic lesions; therefore, its value ranges $0-100 \%$. When calculating it, the Wallace rule of nines [10] is used, in which the surface of the head and each of the upper limbs is $9 \%$ of the body surface, the front and back trunk each 18\% (36\% total), each lower limb $18 \%$, and the crotch area $1 \%$. Alternatively, the socalled rule of the hand can be employed, which assumes that the surface of the patient's hand (without fingers) corresponds to $1 \%$ of the surface of the body.

Finally, DLQI is a questionnaire consisting of 10 questions. Each of the questions concerns the impact of this dermatological disease on various spheres of the patient's life and is rated on a scale of $0-3$. A subjective assessment of the impact of the severity of skin lesions on the patient's quality of life concerns the previous week. The maximum 
number of points reflecting the strongest negative impact of skin lesions on the patient's daily life is $30[10,15]$.

The control group consisted of 9 healthy people (4 women and 5 men), aged 33-63 years (mean age: 44.89 years), without a family history for the presence of psoriasis. Exclusion criteria from participation in the study were pregnancy, lactation and the use of drugs that excessively prolong bleeding time.

This study was conducted in accordance with the principles of good clinical practice and the principles of the Helsinki Declaration. The protocol of this study was approved by the Bioethics Committee of the Medical University of Lodz (resolution No. RNN/15/16/KE of January 9, 2016).

\section{Isolation of T-regulatory lymphocytes (CD4/CD25)} from whole blood

In the venous whole blood collected from all patients, 2-stage selection of T-regulatory lymphocytes was performed. The first step was obtaining CD4+ cells using the RosetteSep ${ }^{\circledR}$ Humane CD4+ T Cell Enrichment Coctail kit (StemCell Technologies, Vancouver, Canada), according to the manufacturer's protocol. In the second stage, CD25+ T lymphocytes were selected from enriched CD4+ cells using the EasySep ${ }^{\circledR}$ Human CD25 Positive Selection Cocktail kit (StemCell Technologies, Vancouver, Canada) and magnetic beads EasySep ${ }^{\circledR}$ Magnetic Nanoparticles (StemCell Technologies, Vancouver, Canada). The positively selected cells were resuspended in $1 \times$ PBS and destined for RNA isolation.

\section{Homogenization of skin biopsies}

Skin samples immediately after excision were placed in a fixRNA buffer (Eurx, Gdańsk, Poland) and stored at $2-8^{\circ} \mathrm{C}$ until use. After the fixRNA buffer was removed, the samples were divided into smaller parts, $600 \mu$ l of lysis buffer was added, and homogenization was performed using a Pellet pestle homogenizer (Sigma-Aldrich, Darmstadt, Germany). Total RNA was isolated from skin homogenates.

\section{RNA isolation, qualitative}

\section{and quantitative RNA evaluation}

Isolation of total RNA from T-regulatory cells and skin homogenates was performed using the mirVana ${ }^{\mathrm{TM}}$ miRNA Isolation Kit (Life Technologies, Carlsbad, USA), according to the manufacturer's protocol. Qualitative and quantitative evaluation of the isolated RNA was performed using the spectrophotometric method, by measuring the absorbance with the Eppendorf BioPhotometerTM Plus apparatus (Eppendorf, Hamburg, Germany), at 260/280 nm wavelengths. Prepared RNA was divided into portions and frozen at $-80^{\circ} \mathrm{C}$ until the real-time polymerase chain reaction (qPCR) was performed.

\section{Evaluation of gene expression}

The reverse transcription (RT) reaction was performed using the High-Capacity cDNA Reverse Transcription Kit (Applied Biosystems, Carlsbad, USA), in a volume of $20 \mu$ l. The reaction mixture contained: $10 \times$ RT buffer, $25 \times \mathrm{dNTP}$ Mix $(100 \mathrm{mM}), 10 \times$ RT Random Primers, MultiScribe ${ }^{\mathrm{TM}}$ Reverse Transcriptase, RNase Inhibitor and nuclease-free water. Overall, $100 \mathrm{ng}$ of total RNA was added to the reaction mixture. The negative control in the RT reaction was carried out using water instead of RNA. The following RT reaction conditions were used: $10 \mathrm{~min}$ at $25^{\circ} \mathrm{C}, 120 \mathrm{~min}$ at $37^{\circ} \mathrm{C}, 5 \mathrm{~min}$ at $85^{\circ} \mathrm{C}$, and cooling at $4^{\circ} \mathrm{C}$.

Relative gene expression was assessed by qPCR using a 7900HT Fast Real-Time PCR System device (Applied Biosystems, Carlsbad, USA). A total reaction volume of $20 \mu$ contained: cDNA (1-100 ng), KAPA PROBE FAST qPCR Master Mix (2X) ABI Prism ${ }^{\text {TM }}$ (Kapa Biosystems Ltd, London, UK), RNAse-free water and $20 \times$ TaqMan $^{\circledR}$ Gene Expression Assay for the following genes: $I L-12 B$ (Hs01011518_m1), TNF (Hs99999043_m1), IL-22 (Hs01574154_m1), IFN- $\gamma$ (Hs00989291_m1) and GAPDH (Hs99999905_m1) selected as the reference gene in qPCR. The relative level of expression of the studied genes was evaluated by the delta-delta CT method (TaqMan Rela- 
tive Quantification Assay software, Applied Biosystems, Carlsbad, USA) and presented as the RQ value relative to the reference gene $G A P D H$. The calibrator for which $\mathrm{RQ}=1$ was the RNA isolated from biological material from a healthy patient, without skin lesions.

\section{Statistical analysis}

The Mann-Whitney U test was used to assess the statistical dependence between the study groups. Spearman's rank correlation coefficient was used to measure the direction and strength of the relationship for individual variables. Statistical analysis was performed using the Statistica 13.1 program (StatSoft, Kraków, Poland). For all statistical analyzes, the statistical significance level was $\mathrm{p}<0.05$. The results (RQ values) are shown as medians.

\section{RESULTS}

\section{$I L-12 B, I L-22$ and $I F N-\gamma$ genes expression in whole group of patients}

The relative expression level of $I L-12 B, I L-22$ and $I F N-\gamma$ genes was analyzed in the material derived from T-regulatory lymphocytes (CD4/CD25) as well as from skin sections. The RQ value of $I F N-\gamma$ in T-regulatory lymphocytes (CD4/ CD25) for $70 \%$ of the samples was increased (RQ $>1$ ) in relation to the calibrator. In the case of $I L-12 B$ and
IL-22, the RQ value was under the detection level. In the skin samples, an increased expression (RQ $>1)$ of all the examined genes was observed when compared to the calibrator: for $I L-12 B$ in $97 \%$ of the samples, while for $I L-22$ and $I F N-\gamma$ in $100 \%$ of the samples. The results indicating median RQ values for the studied genes, and the number of samples with the decreased/increased expression, are presented in Table 1.

The relative expression level of $I L-12 B, I L-22, I F N-\gamma$ in the group of psoriatic patients vs. the control group was compared in the biological material derived from T-regulatory lymphocytes (CD4/CD25) as well as from skin sections. When assessing the level of relative expression in $\mathrm{CD} 4 / \mathrm{CD} 25$, it was shown that the RQ value of $I F N-\gamma$ was increased in both psoriatic and control groups (median RQ: 2.742 and 1.515, respectively). However, the obtained results were not statistically significant $(\mathrm{p}=0.427914$, Mann-Whitney U test). In the case of $I L-12 B$ and $I L-22$, the RQ value was below the detection level for patients both with and without a history of psoriasis. Regarding the biological material derived from skin sections, a statistically significant difference in the relative expression level of $I L-12 B, I L-22$ and $I F N-\gamma$ between the group of psoriatic patients and the control group was observed $(p=0.000107$, $\mathrm{p}=0.0000001, \mathrm{p}=0.000001$, respectively, Mann-Whitney

Table 1. Gene expression levels (relative quantification [RQ]) assessed by the delta-delta CT method and samples with either increased or not increased expression levels, compared with the calibrator in psoriatic adult patients $(\mathrm{N}=30)$, treated in the Department of Dermatology and Venereology and/or the Diagnostic and Treatment Center of Skin Diseases, Łódź, Poland, in March 2016-July 2017

\begin{tabular}{lcccccc}
\hline & \multicolumn{7}{c}{ RQ } \\
\cline { 2 - 6 } Gene & \multicolumn{7}{c}{ skin } & \multicolumn{3}{c}{ lymphocytes (CD4/CD25) } \\
\cline { 2 - 7 } & $\mathrm{Me}$ & $\begin{array}{l}\mathrm{RQ}<1 \\
{[\mathrm{n}(\%)]}\end{array}$ & $\begin{array}{l}\mathrm{RQ}>1 \\
{[\mathrm{n}(\%)]}\end{array}$ & $\mathrm{Me}$ & $\begin{array}{c}\mathrm{RQ}<1 \\
{[\mathrm{n}(\%)]}\end{array}$ & $\begin{array}{c}\mathrm{RQ}>1 \\
{[\mathrm{n}(\%)]}\end{array}$ \\
\cline { 2 - 7 } & 5.363 & $1(3)$ & $29(97)$ & u.d.l. & u.d.l. & u.d.l. \\
$I L-12 B$ & 8.131 & $0(0)$ & $30(100)$ & u.d.l. & u.d.l. & u.d.l. \\
$I L-22$ & 3.810 & $0(0)$ & $30(100)$ & 1.629 & $9(30)$ & $21(70)$ \\
\hline$F N-\gamma$ & & & & & & \\
\hline
\end{tabular}

u.d.l. - under the detection level. 
$\mathrm{U}$ test), with a higher expression of the studied genes in psoriatic patients (Figure 1).

\section{The $R Q$ values of genes vs. clinical features (PASI, BSA, DLQI) of psoriatic patients}

In the researched group, PASI values ranged 3.2-25.4 $(\mathrm{M}=10.76)$, BSA values 7.5-61 $(\mathrm{M}=26.35)$, and DLQI values $0-29(\mathrm{M}=12.4)$.

The relative expression level of $I L-12 B, I L-22, I F N-\gamma$ genes was analyzed depending on the classification of psoriatic patients according to the used scales (PASI, BSA, DLQI). The authors did not find any significant correlation between the expression level of $I F N-\gamma$ and the classification of patients (PASI, BSA, DLQI) in CD4/CD25 ( $p>0.05$, Mann-Whitney U test).

Regarding the biological material derived from skin sections, positive correlations were found between the RQ values of $I L-12 B$ and PASI $(\varrho=0.417725, \mathrm{p}=0.021624$, Spearman's rank correlation coefficient) and also BSA ( $\varrho=0.482198$, $\mathrm{p}=0.006966$, Spearman's rank correlation coefficient) (Figure 2). There were no significant correlations between the RQ values of $I L-22$ and $I F N-\gamma$ genes and the parameters assessing the severity of psoriasis: PASI, BSA, DLQI ( $p>0.05$, Spearman's rank correlation coefficient).

The analysis of the relative expression level of the studied genes between 2 groups of psoriatic patients, with PASI $\leq 10$ vs. PASI $>10$, revealed higher RQ values of $I L-12 B$ and $I F N-\gamma$ in patients with PASI $>10$ (4.149 vs. 12.612 and 3.659 vs. 3.810 , respectively), while the $I L-22$ expression was increased in psoriatic patients with PASI $>10(8.518$ vs. 8.022). The results for $I L-12 B, I L-22, I F N-\gamma$ genes were not statistically significant $(\mathrm{p}=0.084527, \mathrm{p}=0.918485$, $\mathrm{p}=0.983670$, respectively, Mann-Whitney U test).

The relative expression level of the examined genes was also compared depending on the dissemination of skin lesions, dividing the group of patients into 2 subgroups: with $\mathrm{BSA} \leq 20$ vs. BSA $>20$. The RQ values of $I L-12 B$ and $I L-22$ were higher in the group of patients with BSA $>20$
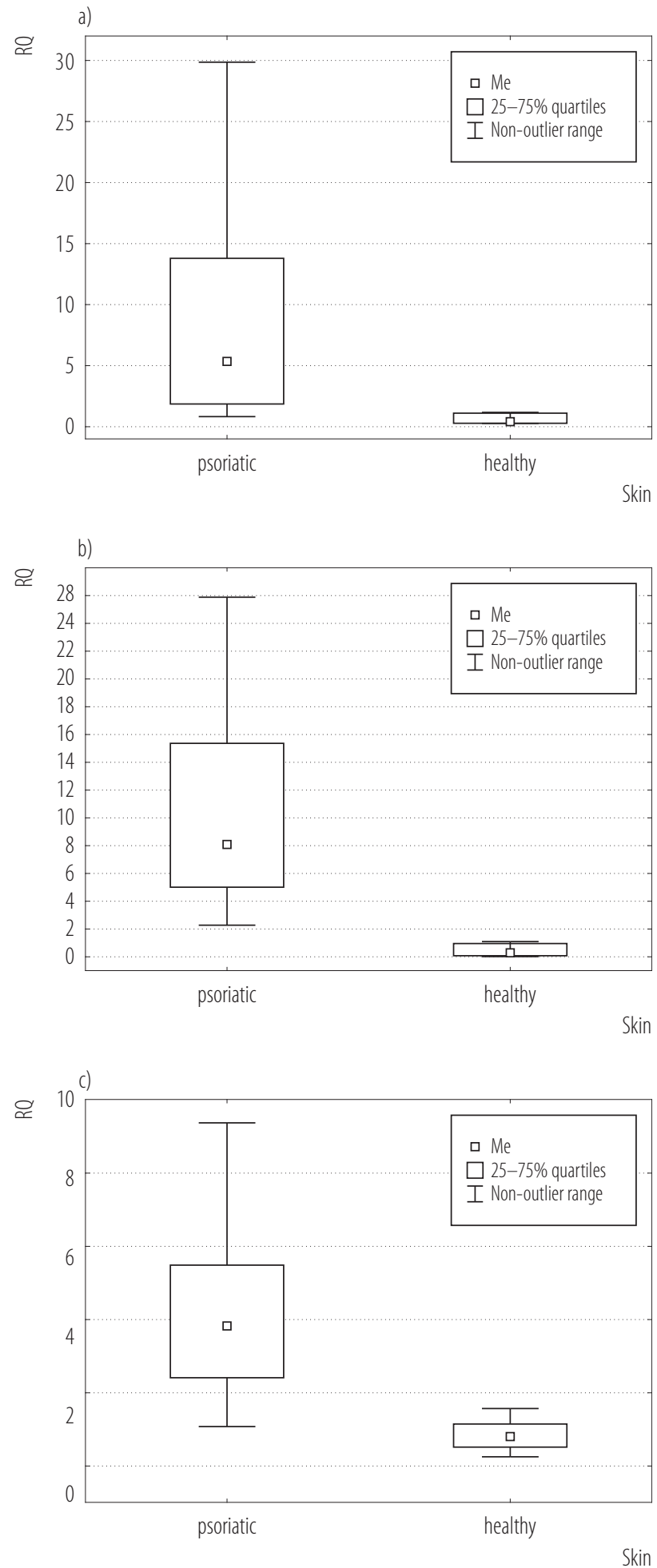

Figure 1. Relative expression levels (median relative quantification $[\mathrm{RQ}]$ values) in psoriatic skin and healthy skin (controls) for genes: a) $I L-12 B$, b) $I L-22$, c) $I F N-\gamma$ 

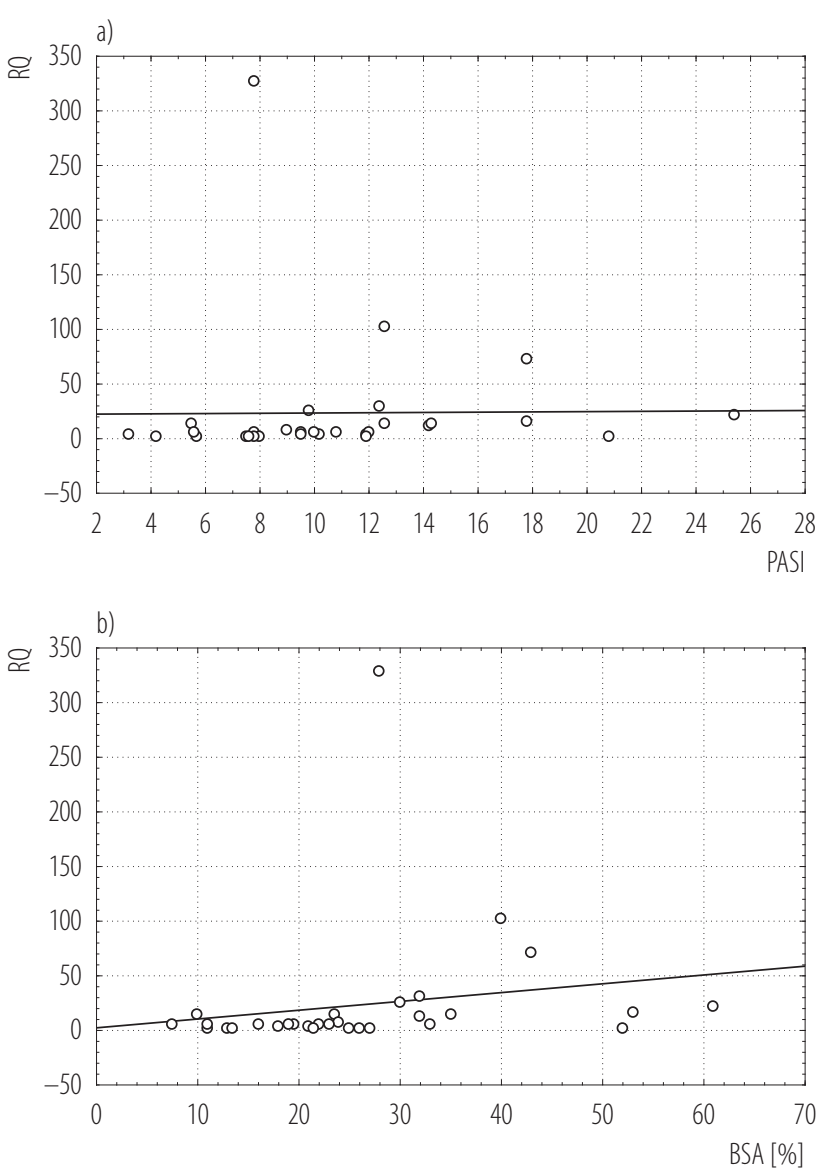

Figure 2. Positive correlation between expression levels (relative quantification [RQ]) of $I L-12 B$ and a) Psoriasis Area and Severity Index (PASI), b) Body Surface Area (BSA)

(4.122 vs. 9.738 and 7.861 vs. 10.500 , respectively), in contrast to IFN- $\gamma$, where in the group of patients with BSA > 20, the RQ value was decreased (5.017 vs. 3.682). No statistically significant differences were found in relation to BSA (IL-12B p $=0.082209, I L-22 \mathrm{p}=0.090570$ and $I F N-\gamma \mathrm{p}=0.745709$, Mann-Whitney $\mathrm{U}$ test). Additionally, by dividing the group of patients according to BSA into 2 subgroups: BSA $\leq 25$ vs. BSA $>25$, the authors observed a significant increase expression of $I L-12 B$ in the group with BSA $>25$ ( $p=0.010450$, Mann-Whitney $\mathrm{U}$ test). The results are presented in Figure 3.

The expression level of $I L-22$ was slightly increased in the BSA > 25 group (6.893200 vs. 9.311500 , respectively)

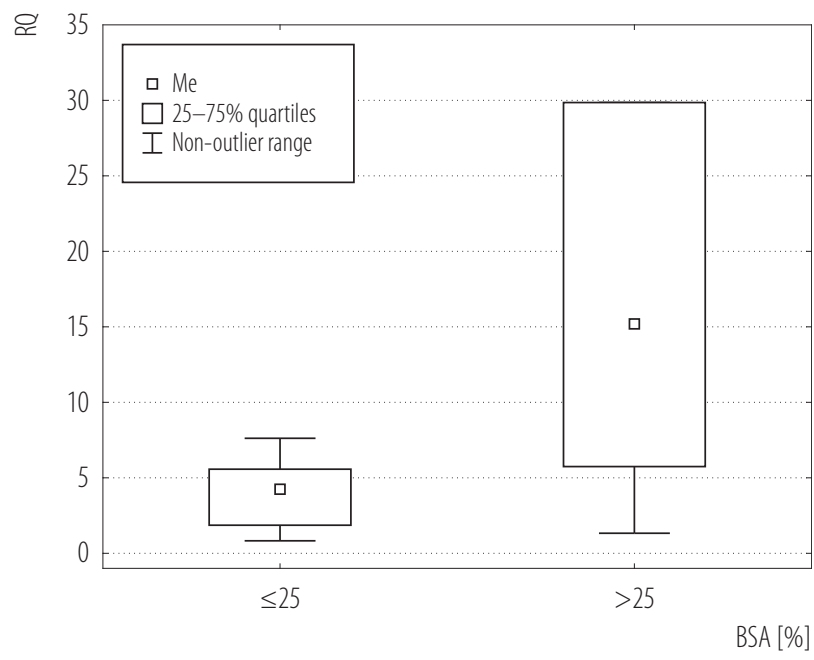

Figure 3. Relative expression levels (median relative quantification [RQ] values) of $I L-12 B$ in psoriatic patients with $\mathrm{BSA} \leq 25$ vs. BSA $>25$

and almost the same median expression level of $I F N-\gamma$ in both groups (3.921100 vs. 3.718600), but without statistical significance $(\mathrm{p}=0.432280$ and $\mathrm{p}=0.836755$, respectively, Mann-Whitney U test).

By dividing the group of psoriatic patients according to DLQI into 2 subgroups: DLQI $\leq 10$ vs. DLQI $>10$, the authors observed higher RQ values of $I L-12 B$ and $I L-22$ in the group with DLQI $>10$ (4.275600 vs. 5.569300 and 7.432700 vs. 8.829500 , respectively), and almost the same expression level of IFN- $\gamma$ in both groups (3.921100 vs. 3.396800). Statistical analysis did not confirm differences in the RQ levels of $I L-12 B, I L-22$ and $I F N-\gamma$ depending on DLQI ( $p=0.982760, p=0.982760$ and $p=0.913961$, respectively, Mann-Whitney $\mathrm{U}$ test).

\section{DISCUSSION}

The etiopathogenesis of psoriasis is not fully elucidated; however, it is known that the immune and inflammatory mechanisms are of decisive importance in its pathogenesis. Understanding the molecular basis and the mechanisms of the disease process will not only contribute to the possibility of expanding the therapeutic offer, but also enable conducting personalized forms of therapy. In order 
to determine the potential factors regulating the development of psoriasis, the expression levels of $I L-12 B, I L-22$ and $I F N-\gamma$ genes in the affected skin and peripheral blood of patients suffering from psoriasis, and in the skin and blood of healthy persons, were examined.

Generally, IL-12 is a cytokine that is a heterodimer composed of 2 subunits marked as p35 (IL-12 $\alpha$ ) and p40 (IL$12 \beta)$. However, neither of the 2 subunits has any bioactivity of its own. Only after the co-expression of p35 and p40, the biologically active p70 heterodimer is formed. Phagocytes and antigen presenting cells (APCs), such as dendritic cells, Langerhans cells and B lymphocytes, are responsible for the production of IL-12 [16,17]. Moreover, T lymphocytes, natural killer (NK) cells, macrophages and dendritic cells are characterized by expression of the receptor for this interleukin. Recent studies have indicated that $\mathrm{T}$ lymphocytes involved in the pathomechanism of psoriasis belong to Th1 cells, and the cytokines produced by them, such as IL-12, interleukin-2 (IL-2) and IFN- $\gamma$, are involved in the pathogenetic mechanisms of this disease [18]. Also, IL-12 has been shown to stimulate the proliferation of Th1 lymphocytes under both in vitro and in vivo conditions [19].

Studies by Yawalkar et al. [20], Cheng et al. [21] and Shaker et al. [22] have shown that the p35 subunit of IL-12 is easily detectable in all biopsies, both in the skin of the control group and in the unchanged skin, as well as in the pathologically changed skin of patients with psoriasis. Omnipresent expression of p35 IL-12 in various cells has also been confirmed by Trinchieri et al. [23] and Ma et al. [24]. They concluded that as p35 subunit of IL-12 seems to be ubiquitous, the expression of the p40 subunit of IL-12 can be thought to be responsible for the increased production of IL-12. Thus, in presented study, the authors evaluated only $I L-12 B$.

The statistical analysis showed that the gene expression level in the group of psoriatic patients, compared to the group of healthy participants, in the case of $I L-12 B$ is significantly higher, which indicates the important role of IL-12 $\beta$ in the development and/or maintenance of psoriatic lesions. Similar relations were found by researchers from the University of Cairo [22] and the University of Bern [20]. On the other hand, since p35 as an IL-12 specific unit does not increase expression in patients with psoriasis, one can conclude that IL-12 does not play such an important role in the pathogenesis of psoriasis. It should be noted that the p40 subunit, in addition to being an IL-12 subunit, is also an IL-23 subunit, which has a particular importance in the etiology of psoriasis. It is also worth mentioning that there are some biological drugs whose mechanism of action is associated with blocking p40 subunits. These include ustekinumab a human monoclonal antibody that binds to the p40 subunit of IL-12 and IL-23 cytokines, and thus blocks their interaction with the IL-12Rb1 receptor [25,26].

Due to its high repeatability and reproducibility, PASI is the most commonly used tool for measuring the severity of psoriasis. The conducted study revealed a positive correlation between PASI and BSA, and the expression level of the $I L-12 B$ gene. The expression levels of $I L-12 B$ were significantly higher in patients with moderate to severe psoriasis (with PASI $>10$ ) than in those with the mild form (PASI $\leq 10)$ of the disease. Moreover, in all analyzed patients, the higher PASI $(>10)$, the higher $I L-12 B$ gene expression was observed. Different results were obtained by Shaker et al. [22] who found no correlation between IL-12 levels in tissues and the PASI result, suggesting that IL-12 influences the development of the disease rather than the severity of skin lesions in the course of psoriasis. A similar relationship for $I L-12 B$ was observed regarding the spread of lesions. The higher level of expression was observed in the group of patients with BSA $>20$ than in the group with BSA $\leq 20$. However, there was no statistical significance between the gene expression levels in the analyzed groups. Most likely, this was due to the divergent number of patients according to the BSA classification: 
10 patients with BSA $\leq 10$ compared to 20 patients with BSA $>20$. Interestingly, by changing the scoring of BSA to $\leq 25$ vs. $>25$ (17 patients vs. 13 patients), the authors observed a statistically significant increase in the expression of $I L-12 B$ for the group with BSA $>25$. It should be emphasized that BSA estimates the extend of psoriasis but not the severity of the disease, because it does not include the morphological features of lesions such as infiltration, erythema and scale [10-12,14].

The level of relative expression in T-regulatory lymphocytes (CD4/CD25) in the case of $I L-12 B$ was below the detection level for both psoriatic patients and healthy people. This means that these genes are not expressed in $\mathrm{CD} 4 / \mathrm{CD} 25$. This is also confirmed by the results of the work by Economidou et al. [27] who found that the plasma levels of IL-12 in patients with psoriasis were not significantly higher than those in healthy subjects. However, they showed a statistically significant decrease in the level of IL-12 in the plasma of patients after 6-month treatment with cyclosporine A.

As regards IL-22, it is a pro-inflammatory cytokine produced mainly by activated lymphocytes such as Th22, Th1, Th17 and NK cells [28-36]. Its function is similar to IL-17 and TNF. Of note, IL-22 acts through a cellular surface receptor composed of 2 subunits: IL-22R1 and interleukin-10 R2 (IL-10R2) [28,37-39]. This receptor complex for IL-22 (IL-22R) is expressed on tissue cells but is absent in blood immune cells [29-31,40], thus IL-22 has no effect on the functioning of immune system cells, both those in retirement and those activated [28,29,41,42]. The target cells for IL-22 are mainly non-hematopoietic cells, e.g., keratinocytes. Then, IL-22 leads to inhibition of the final differentiation [28,43-45]. The activation of CD8+ T cells producing IL-22 in the epidermis causes acanthosis and parakeratosis, which are a histopathological features of psoriasis. Due to the relatively small number of cells having the IL-22R1 receptor, and the total absence of this receptor on cells of the immune system, anti-IL-22 or anti-IL-22R1 drugs might be effective in psoriasis and, theoretically, their use does not cause the systemic immunosuppressive effect [31].

In the performed study, in the group of patients with psoriasis, a significant increase in the expression of $I L-22$ in the psoriatic skin was observed, in comparison to the control group. Similar relationships were found in many other scientific studies [31,46-49]. In addition, Wolk et al. [31] observed that the level of IL-22 mRNA in psoriatic plaques was significantly higher than in the case of IFN- $\gamma$ and interleukin-1 $\beta$ (IL-1 $\beta)$. In another research paper by Wolk et al. [28], the high level of IL-22 expression was again demonstrated in psoriatic lesions, along with an elevated expression of IL-22 regulated genes producing such proteins as S100A7, S100A8, S100A9 (antibacterial proteins) and MMP1 (extracellular matrix metalloproteinase), which indirectly play a role in the pathogenesis of psoriasis. After anti-psoriasis therapy, the level of expression for IL-22 and the genes regulated by this cytokine in the skin lesion samples was reduced. Therefore, the data suggests that IL-22 plays a role in the development and/or maintenance of psoriatic lesions.

However, there was no correlation between the level of IL-22 expression and the PASI or BSA values in all patients, but in the group with moderate and severe psoriasis (PASI >10 and BSA >20), the levels of expression for $I L-22$ were statistically higher. This is consistent with the statements by Hijnen et al. [50] in which the level of expression of the studied cytokines (IL-22, IFN- $\gamma$, IL-13 and IL-17) in the skin biopsies of patients with psoriasis also did not correlate with PASI.

As in the case of $I L-12, I L-22$ genes have not been expressed in $\mathrm{CD} 4 / \mathrm{CD} 25$ because their expression was below the detection level, both in the group of people with psoriasis and in the group of healthy participants. The results of 2 studies performed by Wolk et al. [28,51] were different; they observed high concentrations of IL-22 in the blood plasma of patients with moderate and 
severe psoriasis, and a clear positive correlation with PASI [28].

The lack of expression of $I L-12$ and $I L-22$ genes on CD4/ $\mathrm{CD} 25$, and the presence of their expression in the skin, may confirm their rather local than systemic involvement in the inflammation process in psoriatic patients.

Interferons are a group of cytokines produced and released in response to the presence of pathogens in the body. There are 3 types of interferons. The only representative of type- 2 interferons is IFN- $\gamma$, which has, among others, immunostimulatory and immunomodulatory effects [36]. It induces the infiltration of Th1 cells, and the activation of APCs and endothelial cells [51]. The main source of this cytokine are T lymphocytes (mainly Th1), NK cells, NK T cells and activated macrophages in small amounts [8,36]. It is now believed that a number of inflammatory and autoimmune diseases may be associated with inadequate $I F N-\gamma$ expression.

The mutual relationship between IL-12 and IFN- $\gamma$ should be emphasized. Generally, IL-12 promotes the secretion of IFN- $\gamma$ by $\mathrm{T}$ lymphocytes, and in turn IFN- $\gamma$ induces the production of IL-12 in dendritic cells and/or macrophages - this is called axis IL-12/Th1/IFN- $\gamma$ [8]. In addition, IL-12 is essential for the differentiation of Th1 cells, which are the main place of production of IFN- $\gamma$ [8]. In turn, IFN- $\gamma$ promotes the differentiation of Th0 lymphocytes $(\mathrm{CD} 4+)$ into Th1 cells - this is called the positive feedback loop.

The significant increase in $I F N-\gamma$ gene expression in the skin biopsies of patients with psoriasis was confirmed both in this study and in those carried out by Jiawen et al. [52]. Other scientists also had similar observations [22,53-54]. In addition, Shaker et al. [22] showed that the average level of IFN- $\gamma$ (and IL-12) in the unchanged skin of people suffering from psoriasis was slightly higher than in the control group, but without statistical significance, suggesting that IFN- $\gamma$ plays a direct role in the evolution of psoriatic lesions.
However, there was no correlation between the expression level of the IFN- $\gamma$ gene and the parameters assessing the severity of psoriasis, such as PASI and BSA, but the IFN- $\gamma$ expression levels were higher in the group with PASI $>10$ than in the group with PASI $\leq 10$. The results of this work are consistent with the results obtained by Shaker et al. [22] and by Hijnen et al. [50], who also reported no significant effect of the IFN- $\gamma$ gene expression in psoriatic tissues on the PASI score. Therefore, it can be concluded that the cutaneous levels of IFN- $\gamma$ are not indicative of the severity of the disease.

By assessing the level of relative expression in T-regulatory lymphocytes (CD4/CD25), the authors showed that $I F N-\gamma$ was expressed in these cells, both in psoriatic patients and the control group. Overexpression for $I F N-\gamma$ was observed in both groups, but without any statistically significant differences in the expression levels between the groups for the tested genes. This is probably due to the fact that IFN- $\gamma$ is not a specific marker of the inflammatory process in autoimmune diseases. As a part of the innate immune system, it is released also as a mediator in response to pathogens like viruses, parasites, bacteria and tumor cells [55]. The authors also did not confirm any statistically significant differences in the RQ levels for the studied genes depending on the classification of patients according to PASI, BSA and DLQI, as opposed to Chodorowska et al. [56] who showed that the plasma levels of IFN- $\gamma$ were increased in patients with high PASI, but without statistical significance.

Generally, DLQI is evaluated to determine the impact of the skin disease on the quality of life of a patient suffering from psoriasis. In the present study, no statistically significant differences in the expression levels were found for any of the selected genes for patients with DLQI $\leq 10$ and DLQI $>10$, which suggests that these values do not affect the assessment of the quality of life by psoriatic patients. So, there are probably other causes of the decreased quality of life and other factors should be looked for, such as 
psychosocial determinants, the socio-economic situation of the patient, the emotional background or individual sensitivity.

\section{CONCLUSIONS}

The cells of the immune system play an important role in the initiation and persistence of psoriatic lesions through secreted mediators, but the exact course of the pathogenetic cascade is still not fully clear. Nevertheless, there is no doubt that IL-12, IL-22 and IFN- $\gamma$ play an important role in the etiopathogenesis of psoriasis, both in immune and inflammatory reactions. This is confirmed by a significant increase in the expression levels of these cytokines in the skin of psoriasis patients. Acting independently and through IFN- $\gamma$, IL-12 seems to play a key role in the induction of psoriatic lesions, which is reflected in the positive correlation between this cytokine and the severity of psoriatic lesions as represented by PASI. The lack or weak correlation between $I L-22$ and $I F N-\gamma$ expression levels and PASI may result from the fact that this index includes the assessment of the disease scope - a parameter that appears to be determined also by factors other than the gene expression level. Further research will be required to explain in detail the participation of selected cytokines in the etiopathogenesis of psoriasis.

\section{REFERENCES}

1. Valdimarsson H, Bake BS, Jonsdotdr I, Fry L. Psoriasis A disease of abnormal keratinocyte proliferation induced by T lymphocytes. Immunol Today. 1986;7(9):256-9, https://doi. org/10.1016/0167-5699(86)90005-8.

2. Valdimarsson H, Baker BS, Jonsdottir I, Powles A, Fry L. Psoriasis: a T-cell-mediated autoimmune disease induced by streptococcal superantigens? Immunol Today. 1995;16(3):145-9, https://doi.org/10.1016/0167-5699(95)80132-4.

3. Valdimarsson H, Sigmundsdottir H, Jonsdottir I. Is psoriasis induced by streptococcal superantigens and maintained by M-protein-specific T cells that cross-react with keratin? Clin Exp Immunol. 1997;107(suppl 1):21-4.
4. Cardoso PR, Lima EV, Lima MM, Rego MJ, Marques CD, Pitta Ida R, et al. Clinical and cytokine profile evaluation in Northeast Brazilian psoriasis plaque-type patients. Eur Cytokine Netw. 2016;27(1):1-5, https://doi.org/10.1684/ecn.2016. 0371.

5. Zeng J, Luo S, Huang Y, Lu Q. Critical role of environmental factors in the pathogenesis of psoriasis. J Dermatol. 2017;44(8):863-72, https://doi.org/10.1111/1346-8138.13806.

6. Alesa DI, Alshamrani HM, Alzahrani YA, Alamssi DN, Alzahrani NS, Almohammadi ME. The role of gut microbiome in the pathogenesis of psoriasis and the therapeutic effects of probiotics. J Family Med Prim Care. 2019;8(11):3496-503, https://doi.org/10.4103/jfmpc.jfmpc_709_19.

7. Kamiya K, Kishimoto M, Sugai J, Komine M, Ohtsuki M. Risk factors for the development of psoriasis. Int J Mol Sci. 2019;20(18):4347, https://doi.org/10.3390/ijms20184347.

8. Owczarczyk-Saczonek A, Placek W. [Psoriasis as an autoimmune disease]. Przeg Dermatol. 2014;101:278-87, https:// doi.org/10.5114/dr.2014.45121. Polish.

9. Georgescu SR, Tampa M, Caruntu C, Sarbu MI, Mitran CI, Mitran MI, et al. Advances in understanding in immunological pathways in psoriasis. Int J Mol Sci. 2019;20(3):739, https://doi.org/10.3390/ijms20030739.

10. Bożek A, Reich A. [How to reliably evaluate the severity of psoriasis?] Forum Dermatologicum. 2016;2(1):6-11. Polish.

11. Spuls PI, Lecluse LL, Poulsen ML, Bos JD, Stern RS, Nijsten T. How good are clinical severity and outcome measures for psoriasis? Quantitative evaluation in a systemic review. J Invest Dermatol. 2010;130:933-43, https://doi. org/10.1038/jid.2009.391.

12. Paul C, Gourraud PA, Bronsard V, Prey S, Puzenat E, Aractingi S, et al. Evidence-based recommendations to assess psoriasis severity: systematic literature review and expert opinion of a panel of dermatologists. J Eur Acad Dermatol Venereol. 2010;24(Suppl 2):2-9, https://doi.org/10.1111/ j.1468-3083.2009.03561.x.

13. Langley RG, Ellis CN. Evaluating psoriasis with Psoriasis Area and Severity Index, Psoriasis Global Assessment, 
and Lattice System Physician's Global Assessment. J Am Acad Dermatol. 2004;51:563-9, https://doi.org/10.1016/j.jaad. 2004.04.012.

14. Szepietowski J, Adamski Z, Chodorowska G, Gliński W, Kaszuba A, Placek W, et al. [Diagnostics and treatment of psoriasis vulgaris: guidelines of the Polish Dermatological Society. Part I: mild psoriasis, psoriasis in children]. Przegl Dermatol. 2012;99:83-96. Polish.

15. Finlay AY, Khan GK. Dermatology Life Quality Index (DLQI): a simple practical measure for routine clinical use. Clin Exp Dermatol. 1994;19:210-6, https://doi.org/10.1111/ j.1365-2230.1994.tb01167.x.

16. Gołąb J, Jakóbisiak M, Lasek W, Stokłosa T. Immunologia. Warsaw: PWN SA; 1993.

17. Trinchieri G. Function and clinical use of interleukin 12. Curr Opin Hematol. 1997;4(1):59-66.

18. Schlaak JF, Buslau M, Jochum W, Hermann E, Girndt H, Gallati $\mathrm{H}$, et al. $\mathrm{T}$ cells involved in psoriasis vulgaris belong to the Th1 subset. J Invest Dermatol. 1994;102:145-9, https://doi.org/10.1111/1523-1747.ep12371752.

19. Wong RL, Winslow CM, Cooper KD. The mechanisms of action of cyclosporin $\mathrm{A}$ in the treatment of psoriasis. Immunol Today. 1993;14:69-74, https://doi.org/10.1016/01675699(93)90061-O.

20. Yawalkar N, Karlen S, Hunger R, Brand CU, Braathen LR. Expression of interleukin 12 is increased in psoriatic skin. J Invest Dermatol. 1998;111(6):1053-7, https://doi. org/10.1046/j.1523-1747.1998.00446.x.

21. Cheng J, Tu Y, Li J, Huang C, Liu Z, Liu D. A Study on the Expression of Interleukin (IL)-10 and IL-12 P35, P40 mRNA in the Psoriatic Lesions. J Tongji Med Unic. 2001;21(1):86-8, https://doi.org/10.1007/BF02888047.

22. Shaker OG, Moustafa W, Essmat S, Abdel-Halim M, ElKomy M. The role of interleukin 12 in the pathogenesis of psoriasis. Clin Biochem. 2006;39(2):119-25, https://doi. org/10.1016/j.clinbiochem.2005.11.008.

23. Trinchieri G. Interleukin 12: a proinflammatory cytokine with immunoregulatory functions that bridge innate resis- tance and antigen-specific adaptive immunity. Ann Rev Immunol. 1995;13:251-76, https://doi.org/10.1146/annurev.iy. 13.040195.001343.

24. Ma X, Aste-Amezaga M, Gri G, Gerosa F, Trinchieri G. Immunomodulatory functions and molecular regulation of IL-12. Chem Immunol. 1997;68:1-22, https://doi.org/10. 1159/000058687.

25. Wcisło-Dziadecka D, Grabarek B, Kruszniewska-Rajs C, Strzałka-Mrozik B. The analysis of the therapeutic potential of ustekinumab in psoriasis vulgaris treatment. Dermatol Ther. 2019;32(3):e12843, https://doi.org/10.1111/dth.12843.

26. Rendon A, Schäkel K. Psoriasis pathogenesis and treatment. Int J Mol Sci. 2019;20(6):1475, https://doi.org/10.3390/ ijms20061475.

27. Economidou J, Barkis J, Demetriou Z, Avgerinou G, Psarra K, Degiannis D, et al. Effects of Cyclosporin A on Immune Activation Markers in Patients with Active Psoriasis. Dermatology. 1999;199(2):144-8, https://doi.org/10.1159/00 0018222.

28. Wolk K, Witte E, Wallace E, Docke WD, Kunz S, Asadullah K, et al. IL-22 regulates the expression of genes responsible for antimicrobial defense, cellular differentiation, and mobility in keratinocytes: a potential role in psoriasis. Eur J Immunol. 2006;36(5):1309-23, https://doi.org/10.1002/eji. 200535503.

29. Wolk K, Kunz S, Asadullah K, Sabat R. Cutting edge: immune cells as sources and targets of the IL-10 family members? J Immunol. 2002;168:5397-402, https://doi.org/ 10.4049/jimmunol.168.11.5397.

30. Wolk K, Witte K, Witte E, Proesch S, Schulze-Tanzil G, Nasilowska K, et al. Maturing dendritic cells are an important source of IL-29 and IL-20 that may cooperatively increase the innate immunity of keratinocytes. J Leukoc Biol. 2008;83:1181-93, https://doi.org/10.1189/jlb.0807525.

31. Wolk K, Kunz S, Witte E, Friedrich M, Asadullah K, Sabat R. IL-22 increases the innate immunity of tissues. Immunity. 2004;21:241-54, https://doi.org/10.1016/j.immuni.2004. 07.007 . 
32. Chung Y, Yang X, Chang SH, Ma L, Tian Q, Dong C. Expression and regulation of IL-22 in the IL-17-producing CD4+ T lymphocytes. Cell Res. 2006;16:902-7, https://doi. org/10.1038/sj.cr.7310106.

33. Liang SC, Tan XY, Luxenberg DP, Karim R, DanussiJoannopoulos K, Collins M, et al. Interleukin (IL)-22 and IL-17 are coexpressed by Th17 cells and cooperatively enhance expression of antimicrobial peptides. J Exp Med. 2006;203:2271-9, https://doi.org/10.1084/jem.20061308.

34. Zheng Y, Danilenko DM, Valdez P, Kasman I, Eastham-Anderson J, Wu J, et al. Interleukin 22, a T(H)17 cytokine, mediates IL-23-induced dermal inflammation and acanthosis. Nature. 2007;445:648-51, https://doi.org/10.1038/nature05505.

35. Hwang YJ, Jung HJ, Kim MJ, Roh NK, Jung JW, Lee YW, et al. Serum levels of LL-37 and inflammatory cytokines in plaque and guttate psoriasis. Mediators Inflamm. 2014;2014:268257, https://doi.org/10.1155/2014/268257.

36. Michalak-Stroma A, Pietrzak A, Szepietowski JC, Zalewska-Janowska A, Paszkowski T, Chodorowska G. Cytokine network in psoriasis revisited. Eur Cytokine Netw. 2011;22(4):160-8, https://doi.org/10.1684/ecn.2011.0294.

37. Dumoutier L, Van Roost E, Colau D, Renauld JC. Human interleukin-10-related $\mathrm{T}$ cell-derived inducible factor: molecular cloning and functional characterization as an hepatocyte-stimulating factor. Proc Natl Acad Sci USA. 2000;97:10144-9, https://doi.org/10.1073/pnas.170291697.

38. Xie MH, Aggarwal S, Ho WH, Foster J, Zhang Z, Stinson J, et al. Interleukin (IL)-22, a novel human cytokine that signals through the interferon receptor-related proteins CRF2-4 and IL-22R. J Biol Chem. 2000;275:31335-9, https://doi. org/10.1074/jbc.M005304200.

39. Kotenko SV, Izotova LS, Mirochnitchenko OV, Esterova E, Dickensheets H, Donnelly RP, et al. Identification of the functional interleukin 22 (IL-22) receptor complex: the IL-10R2 chain (IL-10Rbeta) is a common chain of both the IL-10 and IL-22 (IL-10-related T cell-derived inducible factor, IL-TIF) receptor complexes. J Biol Chem. 2001;276:2725-32, https:// doi.org/10.1074/jbc.M007837200.
40. Wolk K, Witte E, Reineke U, Witte K, Friedrich M, Sterry $\mathrm{W}$, et al. Is there an interaction between interleukin-10 and interleukin 22? Genes Immun. 2005;6:8-18, https:/doi. org/10.1038/sj.gene.6364144.

41. Lejeune D, Dumoutier L, Constantinescu S, Kruijer W, Schuringa JJ, Renauld JC. Interleukin 22 (IL-22) activates the JAK/STAT, ERK, JNK, and p38 MAP kinase pathways in a rat hepatoma cell line. Pathways that are shared with and distinct from IL-10. J Biol Chem. 2002;277:33676-82, https://doi.org/10.1074/jbc.M204204200.

42. Aggarwal S, Xie MH, Maruoka M, Foster J, Gurney AL. Acinar cells of the pancreas are a target of interleukin 22. J Interferon Cytokine Res. 2001;21:1047-53, https://doi.org/ 10.1089/107999001317205178.

43. Lowes MA, Bawcock AM, Krueger JG. Pathogenesis and therapy of psoriasis. Nature. 2007;445:866-73, https:/doi. org/10.1038/nature05663.

44. Milijkovic D, Trajkovic V. Inducible nitric oxide synthase activation by interleukin-17. Cytokine Growth Factor Rev. 2004;15:21-32, https://doi.org/10.1016/j.cytogfr.2003.10.003.

45. Boniface K, Bernard FX, Garcia M, Gurney AL, Lecron JC, Morel F. IL-22 inhibits epidermal differentiation and induces proinflammatory gene expression and migration of human keratinocytes. J Immunol. 2005;174:3695-702, https:// doi.org/10.4049/jimmunol.174.6.3695.

46. Kunz S, Wolk K, Witte E, Witte K, Doecke WD, Volk HD, et al. Interleukin (IL)-19, IL-20 and IL-24 are produced by and act on keratinocytes and are distinct from classical ILs. Exp Dermatol. 2006;15:991-1004, https://doi.org/10.1111/j.16000625.2006.00516.x.

47. Otkjaer K, Kragballe K, Funding AT, Clausen JT, Noerby PL, Steiniche T, et al. The dynamics of gene expression of interleukin-19 and interleukin-20 and their receptors in psoriasis. Br J Dermatol. 2005;153:911-8, https://doi.org/10.1111/ j.1365-2133.2005.06800.x.

48. Romer J, Hasselager E, Norby PL, Steiniche T, Clausen JT, Kragballe K. Epidermal overexpression of interleukin-19 and -20 mRNA in psoriatic skin disappears after short-term 
treatment with cyclosporin a or calcipotriol. J Invest Dermatol. 2003;121:1306-11.

49. Wei CC, Chen WY, Wang YC, Chen PJ, Lee JY, Wong TW, et al. Detection of IL-20 and its receptors on psoriatic skin. Clin Immunol. 2005;117:65-72, https://doi.org/10.1016/j.clim. 2005.06.012.

50. Hijnen D, Knol EF, Gent YY, Giovannone B, Beijn SJ, Kupper TS, et al. CD8+ T Cells in the Lesional Skin of Atopic Dermatitis and Psoriasis Patients Are an Important Source of IFN- $\gamma$, IL-13, IL-17, and IL-22. J Invest Dermatol. 2013;133(4):973-9, https://doi.org/10.1038/jid.2012.456.

51. Wolk K, Witte E, Warszawska K, Schulze-Tanzii G, Witte K, Philipp S, et al. The Th17 cytokine IL-22 induces IL-20 production in keratinocytes: a novel immunological cascade with potential relevance in psoriasis. Eur J Immunol. 2009;39:3570-81, https://doi.org/10.1002/eji.200939687.

52. Li J, Li D, Tan Z. The expression of interleukin-17, interferon gamma, and macrophage inflammatory protein-3 alpha mRNA in patients with psoriasis vulgaris. J Huazhong Univ Sci Technolog Med Sci. 2004;24(3):294-6, https://doi. org/10.1007/BF02832018.
53. Austin LM, Ozawa M, Kikuchi T, Walters IB, Krueger JG. The majority of epidermal $\mathrm{T}$ cell in psoriasis vulgaris lesions can produce type 1 cytokines, interferon gamma, interleukin 2 and tumor necrosis factor alpha, defining Tc1 (cytotoxic T lymphocyte) and Th 1 effector populations: a type 1 differentiation bias is also measured in circulating blood T cells in psoriatic patients. J Invest Dermatol. 1999;113(5):752-9, https://doi.org/10.1046/j.1523-1747.1999.00749.x.

54. Uyemura K, Yamamura M, Fivenson DF, Modlin RL, Nickoloff BJ. The cytokine network in lesional and lesion free psoriatic skin is characterized by a T helper type 1 cell mediated response. J Invest Dermatol. 1993;101(5):701-5, https:// doi.org/10.1111/1523-1747.ep12371679.

55. Kak G, Raza M, Tiwari BK. Interferon gamma (IFN- $\gamma$ ): Exploring its implications in infectious disease. Biomol Concepts. 2018; 9(1):64-79, https://doi.org/10.1515/bmc-2018-0007.

56. Chodorowska G. Plasma concentrations of IFN-gamma and TNF-alpha in psoriatic patients before and after local treatment with dithranol ointment. J Eur Acad Dermatol Venereol. 1998;10(2):147-51, https://doi.org/10. 1111/j.1468-3083.1998.tb00715.x.

This work is available in Open Access model and licensed under a Creative Commons Attribution-NonCommercial 3.0 Poland License - http://creativecommons.org/ licenses/by-nc/3.0/pl/deed.en. 